\title{
Takashi Gomi, vision and ethics
}

Prof. Francesco Mondada

Ecole Polytechnique Fédérale de Lausanne, Switzerland

The tribute of Inman Harvey picks very well the key elements of the action of Takashi Gomi. I will just add some impressions and lessons I got from my friendship with him.

I met Takashi Gomi in March 1993, at the NATO sponsored Advanced Study Institute held in Trento, Italy. Luc Steels, organizer of the workshop, managed to bring together the robotics community following Rod Brooks and his Behavior Based Robotics, the emerging community working on evolutionary robotics and people, like me, working on new paradigms such as neural networks. I met there other people who changed my life: Dario Floreano, Stefano Nolfi, Inman Harvey and many others. I was there to present the first prototype of the Khepera robot controlled by an artificial neural network developed with Paul Verschure and Rolf Pfeifer.

Like all people that were there, both Takashi and me were sharing the same enthusiasm for a new form of robotics. We were discussing all day about embodiment in real robots and new paradigms of robotic control. In addition to that, both Takashi and me were interested in spreading these concepts and the related technology by distributing robotic hardware and enable an experimental diffusion of these ideas. Takashi Gomi was already reselling the robots produced by IS-Robotics, the company founded by Rod Brooks that became later I-robot. Takashi immediately saw in the Khepera robot an additional tool to bring robotics to a much larger audience. Khepera was much smaller and cheaper than existing robots, still having similar performances in obstacle perception. Its size made it mechanically robust, enabling new approaches such as evolutionary robotics. With Khepera it was possible to work on a table, removing infrastructural problems and allowing a control from any computer in any programming environment. Takashi saw that these advantages would allow a much larger community to use physical robots, and became its best ambassador. Khepera became a product and more than the half of the production, in the following years, went to Japanese research centers. In Japan and in Europe the small size of Khepera was very appreciated and new $A I$ was a trend, while in the US, for instance, Khepera was perceived as a toy. Only later Khepera entered in the US market, but with much less success. Today, on google scholar, one can find more than 5000 publications mentioning the Khepera robot. Takashi was extremely good in feeling the potential impact of a technology or a concept. He saw the potential of the Khepera robot concept from the beginning and translated it into a success by his action.

When I left the company producing Khepera and designed the e-puck robot at the Ecole Polytechnique Fédérale de Lausanne (EPFL), Takashi became immediately again a reseller of this open-source robot. He even started producing it in large quantities in Japan, becoming the second manufacturer of this robot. He established a great relationship with the Swiss manufacturer of the robot, Gilles Caprari, who also shares the same motivations and working principles.

Takashi Gomi was following his ideas with extreme passion, a solid social engagement and strong ethic principles. Profit has never been a motivation for him. His motivation was helping society to progress, following clear ethical principles 
based on the respect of the human being. He and his employees were ready to delay the payment of their salary to allow the financial support of a workshop they felt important for the progress of the field and the improvement of society. He organized during many years the Evolutionary Robotics symposium in Japan, making the bridge between academic world and industry, spreading the concepts of new AI. He sponsored heavily this activity from his economically weak company, even if this was not bringing direct income. Coherent with his ideas about respect of life, he refused several times to make very good sales to some governmental institutes, because they were developing technology for the army. These were, for him, dark applications. He would have preferred to not be paid for his work than contributing to the creation of weapons. Although I personally shared his convictions, I was always impressed by the coherence of his action and of his whole company, and how they were all ready to live with the consequences of the decisions taken.

Takashi Gomi was visionary not only in the field of robotics, but for the society as a whole. His company was a component of society and he was taking this aspect very seriously. He was applying his principles within the company and using the company to impact society, from industry to the academic world. He always strongly criticized our society increasingly based on profit and economic principles, for instance. He even predicted a global crash of this model at the international level. In some sense he anticipated the Global Financial Crisis of 2008 with an incredible clear-sightedness.

As we were both extremely passionate about our work and were sharing the same approaches, most of the time we managed to work together very well, but every small divergence resulted in strong fights. One reason of fight was for instance time pressure: he was convinced that products should be delivered as fast as possible to customers, even if not fully finalized, and I was convinced that we should deliver the best products, well finalized, even if this would take longer. Even in these situations we were both aware that these fights were the result of our passion for the field, and every conflict reinforced our friendship and mutual respect. This made our relationship unique and strong.

Takashi Gomi leaves a huge gap but also a rich heritage. He leaves a set of actions that transformed the field of robotics and a strong example for all people working in robotics and science in general. In every actions of Takashi there is a fervent message to improve the way of acting in a field where ethical principles are not always respected, where passion is not always the main motivation, where the improvement of society has sometimes a lower priority than bibliometrics, where some people lose motivation or end in a burn-out. This message full of energy should help us to stay on course with clear-sightedness and courage, innovate, fight for truth, respect our environment and improve it, exactly like he did. 


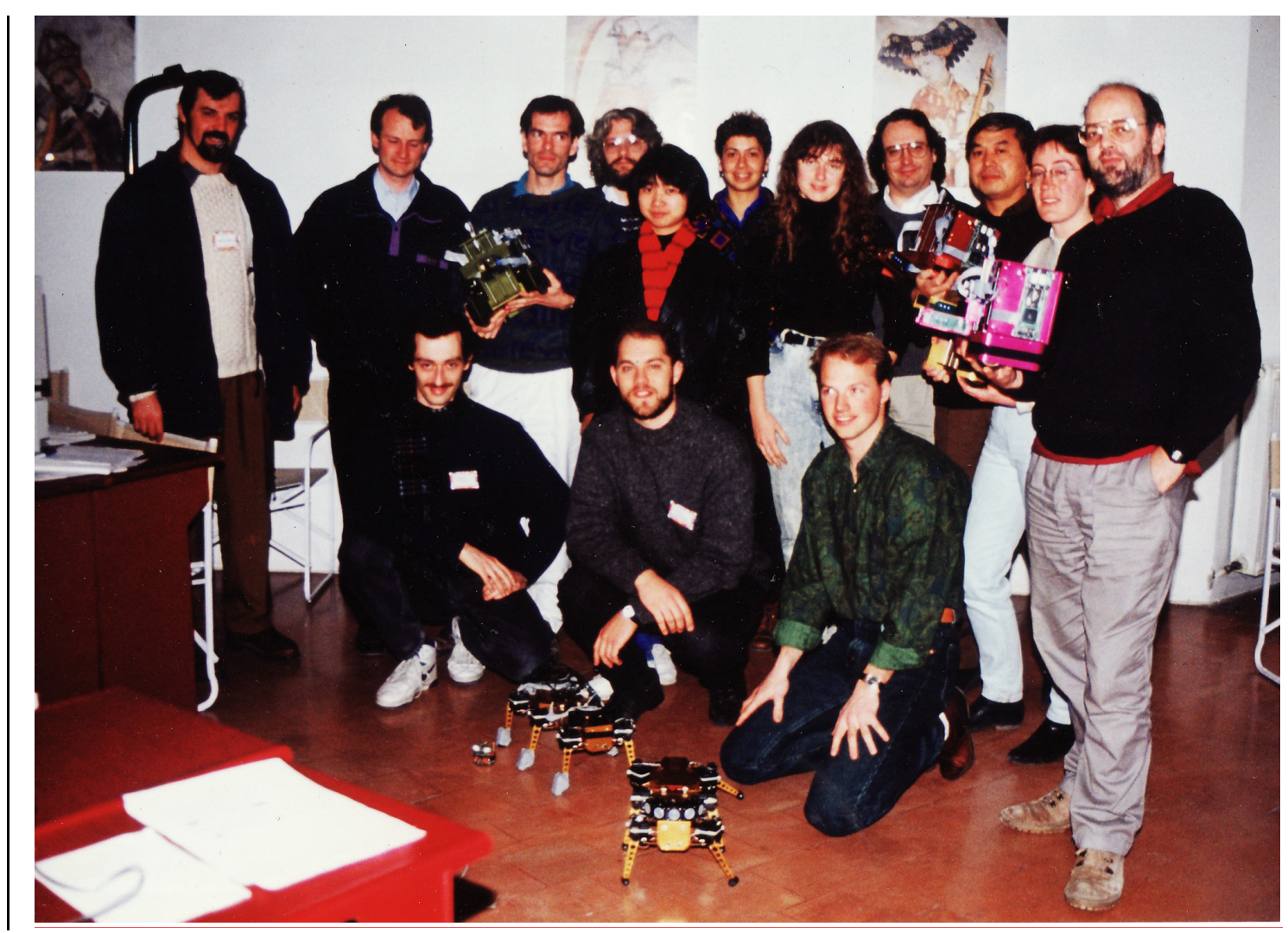

Figure 1: Part of the participants of the 1993 NATO workshop in Trento, in a session about robot programming. To mention a few, in the main row, from right to left: Inman Harvey, Joanna Bryson, Takashi Gomi, Rodney Brooks, Maja Mataric, Unamay O'Riley and, left most, Pierre Marchal. In the front row from right to left: Sebastian Thrun, Kristian Simsarian and Francesco Mondada. The Khepera robot is on the left of all robots, near a leg of the bigger Gengis robot... the two spots are the reflection of the flash on the lenses of the cameras (Photo: Kristian Simsarian)
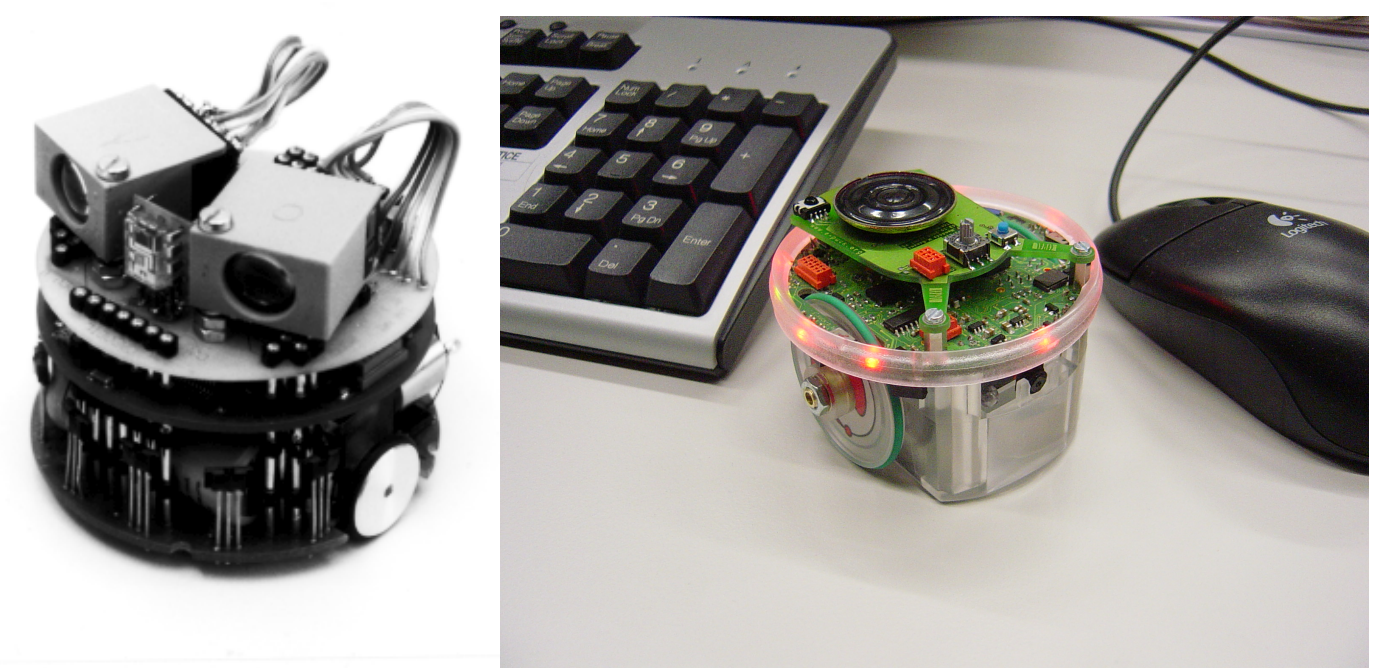

Figure 2: Left: Khepera robot as it was presented at the 1993 NATO workshop in Trento (see also fig. 1). Right: the e-puck robot has a similar size. 